\title{
Triaminic Allergy Congestion
}

National Cancer Institute

\section{Source}

National Cancer Institute. Triaminic Allergy Congestion. NCI Thesaurus. Code C29513.

Any commercial combination preparation, by Novartis, containing the decongestant pseudoephedrine hydrochloride used to relieve symptoms of cold and flu.

Pseudoephedrine hydrochloride, a sympathomimetic agent, stimulates alpha-adrenergic receptors and causes vasoconstriction. This reduces blood flow, decreases swelling and prevents nasal and sinus congestion. 